Pacific Journal of Mathematics

NEGATIVE THEOREMS ON GENERALIZED CONVEX 


\title{
NEGATIVE THEOREMS ON GENERALIZED CONVEX APPROXIMATION
}

\author{
Eli Passow AND JoHN A. ROULIER
}

In this paper we show that there exist functions $f \in C[-1$, +1 ] with all $(r+1)$-st order divided differences uniformly bounded away from zero for $r$ fixed $\left(f\left[x_{0}, x_{1}, \cdots, x_{r+1}\right] \geqq \delta>0\right.$ for fixed $\delta$ and all sets $x_{0}<\cdots<x_{r+1}$ in $\left.[-1,+1]\right)$, for which infinitely many of the polynomials of best approximation to f do not have nonnnegative $(r+1)$-st derivatives on $[-1,+1]$.

1. Introduction. In [6]-[10] there appear many examples of functions $f$ in $C[a, b]$ with nonnegative $(r+1)$-st divided differences there for which infinitely many of the polynomials of best approximation to $f$ fail to have nonnegative $(r+1)$ st derivatives. None of these examples has the $(r+1)$ st divided differences uniformly bounded away from zero. In [11] Roulier shows that if $f \in C^{2 r+2}[-1$, $+1]$ and if $f^{(r+1)}(x) \geqq \delta>0$ on $[-1,1]$ then for $n$ sufficiently large the polynomial of best approximation of degree less than or equal to $n$ has a positive $(r+1)$ st derivative on $[-1,+1]$.

On the other hand for the case $r=0$ Roulier in [12] shows that first divided differences of $f$ uniformly bounded away from zero is not sufficient to insure that for $n$ sufficiently large the polynomial of best approximation to $f$ is increasing on $[-1,1]$.

In this paper we extend the results of [12] to the case when $r \geqq 0$. The proofs are similar to those in [12] but make use of higher order divided differences and their properties.

2. Notation and preliminary concepts. For $n=0,1,2, \cdots$ define $H_{n}$ to be the set of all algebraic polynomials of degree less than or equal to $n$. For $f \in C[a, b]$, let

$$
\|f\|=\sup \{|f(x)|: a \leqq x \leqq b\} \text {. }
$$

We define the degree of approximation to $f$ to be

$$
E_{n}(f)=\inf \left\{\|f-p\|: p \in H_{n}\right\},
$$

$n=0,1,2, \cdots$. It is well-known that there is a unique $p_{n} \in H_{n}$ for which $\left\|f-p_{n}\right\|=E_{n}(f)$. This $p_{n}$ is called the polynomial of best approximation to $f$ on $[a, b]$ from $H_{n}$. Unless specifically stated otherwise we will restrict ourselves to the interval $[-1,+1]$.

Define $C^{*}$ to be the class of continuous $2 \pi$-periodic functions and $H_{n}^{*}$ the trigonometric polynomials of degree $n$ or less. Then 
$E_{n}{ }^{*}(f)$ is defined for $f \in C^{*}$ as the degree of approximation to $f$ by trigonometric polynomials from $H_{n}^{*}$. That is,

$$
E_{n}^{*}(f)=\inf \left\{\|f-T\|^{*}: T \in H_{n}^{*}\right\}
$$

where

$$
\|f\|^{*}=\sup \{|f(x)|:-\pi \leqq x \leqq \pi\} .
$$

If $I=[-1,1]$ or $I=[-\pi, \pi]$ and $f \in C[-1,+1]$ or $f \in C^{*}$ we define the r-th modulus of smoothness $\omega_{r}(f, h)=\sup \left\{\left|\Delta_{t}^{r} f(x)\right|:|t| \leqq h\right.$ and $r h \leqq|I|\}$, where $\Delta_{t}^{1} f(x)=f(x+t)-f(x)$ and $\Delta_{t}^{r} f(x)=\Delta_{t}^{1}\left(\Delta_{t}^{r-1} f(x)\right)$, and $|I|$ is the length of $I$.

If $r=1$ then $\omega_{r}(f, h)$ is called the modulus of continuity of $f$ and is written $\omega(f, h)$.

Estimates for $E_{n}(f)$ are intimately related to $\omega_{r}(f, h)$ by the theorems of D. Jackson. These theorems are well-known and will not be given here. See [5].

As in [3] let $f\left[x_{0}, \cdots, x_{r}\right]$ denote the $r$ th order divided difference of $f$. It is well-known that if $f \in C^{r}\left[x_{0}, x_{r}\right]$ and $x_{0}<x_{1}<\cdots<x_{r}$ then there is $\xi$ in $\left(x_{0}, x_{r}\right)$ for which

$$
f^{(r)}(\xi)=r ! f\left[x_{0}, \cdots, x_{r}\right] \text {. }
$$

It is also well-known that if all $(r+1)$ st order divided differences of $f$ are nonnegative in $[-1,+1]$ then $f \in C^{r-1}(-1,+1)$. See [2].

In the following sections, $p_{n}$ will always denote the polynomial from $H_{n}$ of best approximation to $f$ on the appropriate interval.

3. The main theorems. The following theorems treat the situations where all $(r+1)$ st order divided differences of $f$ are bounded away from zero on $[-1,+1]$ and $f \in C^{r-1}[-1,+1]$ or $f \in C^{r}[-1,+1]$. The first two theorems and their corollaries show that for all functions with nonnegative $(r+1)$ st order divided differences for which $E_{n}(f)$ does not get small too fast there are infinitely many $n$ for which we do not have $p_{n}^{\langle r+1\rangle}(x) \geqq 0$ on $[-1,+1]$. The last two theorems show that this will also occur for some functions with $(r+1)$ st order divided differences bounded away from zero even if $E_{n}(f)$ does get small faster than allowed in the first two theorems.

THEOREM 3.1. Let $f \in C[-1,1]$ have bounded $r$ th order divided differences (if $f \in C^{r}[-1,1]$, then this happens) and nonnegative $(r+1)$ st order divided differences on $[-1,+1]$. Assume that there is no $C>0$ for which

$$
E_{n}(f) \leqq C /(n+1)^{r+1} \text { for } n=0,1, \cdots .
$$


Then there are infinitely many $n$ for which we do not have $p_{n}^{\langle r+1\rangle}(x) \geqq 0$ on $[-1,+1]$.

COROLlary 3.1(a). Let $f \in C^{r}[-1,+1]$ and assume that $f$ has nonnegative $(r+1)$ st order divided differences on $[-1,+1]$. Define $g(t)=f(\cos t)$. Assume that

$$
\limsup _{k \rightarrow \infty} k^{r+1} \omega_{r+1}\left(g, \frac{1}{k}\right) / \log k=+\infty .
$$

Then there are infinitely many $n$ for which we do not have $p_{n}^{\langle r+1\rangle}(x) \geqq 0$ on $[-1,+1]$.

COROLlaRY 3.1(b). If $f$ has nonnegative $(r+1)$ st order divided differences on $(-1-\epsilon, 1+\epsilon)$ for some $\epsilon>0$ and if there is no $C>0$ for which

$$
E_{n}(f) \leqq C /(n+1)^{r+1} \quad \text { for } \quad n=0,1, \cdots
$$

then there are infinitely many $n$ for which we do not have

$$
p_{n}^{\langle r+1\rangle}(x) \geqq 0 \quad \text { on } \quad[-1,+1] \text {. }
$$

THEOREM 3.2. Let $f \in C^{r-1}[-1,+1]$ and assume that $f$ has nonnegative $(r+1)$ st order divided differences. Assume that there is no $C>0$ for which

$$
E_{n}(f) \leqq C /(n+1)^{r} \quad \text { for } \quad n=0,1, \cdots .
$$

Then there are infinitely many $n$ for which we do not have $p_{n}^{\langle r+1\rangle}(x) \geqq 0$ on $[-1,+1]$.

CoROLlary 3.2. Let $f \in C^{r-1}[-1,+1]$ and assume that $f$ has nonnegative $(r+1)$ st order divided differences. Define

$$
g(t)=f(\cos t) .
$$

Assume that

$$
\limsup _{k \rightarrow \infty} k^{r} \omega_{r}\left(g, \frac{1}{k}\right) / \log k=+\infty .
$$

Then there are infinitely many $n$ for which we do not have $p_{n}^{\langle r+1\rangle}(x) \geqq 0$ on $[-1,+1]$.

THEOREM 3.3. For each integer $r \geqq 0$ and modulus of continuity $\omega$ there exists $f \in C^{r}[-1,+1]$ with 


$$
f\left[x_{0}, \cdots, x_{r+1}\right] \geqq \delta>0 \text { for all } x_{0}<\cdots<x_{r+1}
$$

in $[-1,+1]$ and with

$$
\omega(h) \leqq \omega\left(f^{(r)}, h\right) \leqq K \omega(h)
$$

and yet there are infinitely many $n$ for which we do not have $p_{n}^{\langle r+1\rangle}(x) \geqq 0$.

THEOREM 3.4. For each integer $r \geqq 1$ and modulus of continuity $\omega$ there exists $f \in C^{r-1}[-1,+1]$ with

$$
f\left[x_{0}, \cdots, x_{r+1}\right] \geqq \delta>0 \text { for all } x_{0}<\cdots<x_{r+1}
$$

in $[-1,+1]$ and with

$$
\omega(h) \leqq \omega\left(f^{(r-1)}, h\right) \leqq K \omega(h)
$$

and yet there are infinitely many $n$ for which we do not have $p_{n}^{\langle r+1\rangle}(x) \geqq 0$.

4. Proofs of the main theorems. We first state some known lemmas. The first lemma is due to Steckin [13] and is found in [5] page 59.

Lemma 4.1. There exist constants $M_{p}, p=1,2, \cdots$, such that for each $f \in C^{*}$

$$
\omega_{p}(f, h) \leqq M_{p} h^{p} \sum_{0 \leqq n \leqq h-1}(n+1)^{p-1} E_{n}^{*}(f) .
$$

Lemma 4.2. Let $f \in C[-1,+1]$ and define $g \in C^{*}$ by $g(t)=$ $f(\cos t) . \quad I f$

$$
\limsup _{k \rightarrow \infty} k^{r+1} \omega_{r+1}\left(g, \frac{1}{k}\right) / \log k=+\infty,
$$

then there does not exist $M>0$ for which

$$
E_{n}(f) \leqq M /(n+1)^{r+1}, \text { for } n=0,1,2, \cdots .
$$

Proof. Assume such a constant $M$ exists. Then $E_{n}^{*}(g)=$ $E_{n}(f) \leqq M /(n+1)^{r+1}$ for $n=0,1, \cdots$. Now use Lemma 4.1 with $h=1 / N$. This gives

$$
\omega_{r+1}(g, 1 / N) \leqq \frac{A_{r}}{N^{r+1}} \sum_{n=0}^{N} \frac{1}{n+1} \leqq \frac{K_{r} \log N}{N^{r+1}} .
$$

Hence 


$$
N^{r+1} \omega_{r+1}(g, 1 / N) / \log N \leqq K_{r} .
$$

This is a contradiction.

The next lemma is stated in [12] and is a simple consequence of a theorem of Kadec [4].

LEMMA 4.3. Let $f \in C[-1,+1]$ and for each $n=0,1,2, \cdots$ let $x_{0, n}<\cdots<x_{n+1, n}$ be a Chebyshev alternation for $f$.

Let $\delta_{n}=\max _{0 \leqq k \leqq n+1}\left|x_{k, n}-\cos (k \pi /(n+1))\right|$. Then there is a sequence $\left\{n_{j}\right\}_{j=0}^{\infty}$ of positive integers for which

$$
\lim _{j \rightarrow \infty} \delta_{n_{j}}=0 \text {. }
$$

The next lemma is found in [5] page 45 .

Lemma 4.4. Let $\omega$ be any modulus of continuity. Then there is a concave modulus of continuity $\bar{\omega}$ with the same domain of definition as $\omega$ for which

$$
\frac{1}{2} \bar{\omega}(h) \leqq \omega(h) \leqq \bar{\omega}(h)
$$

The next lemma is well-known. We first define for $r=1,2, \cdots$

$$
x_{+}^{r}=\left\{\begin{array}{lll}
0 & \text { for } & x \leqq 0 \\
x^{r} & \text { for } & x>0
\end{array} .\right.
$$

Lemma 4.5. There is a constant $C_{r}>0$ for which

$$
E_{n}\left(x_{+}^{r}\right) \geqq C_{r} /(n+1)^{r} .
$$

Proof. This is an easy consequence of a theorem of S. N. Bernstein [1].

Lemma 4.6. If there are $m$ non-overlapping intervals $I_{1}, \cdots, I_{m}$ contained in $[a, b]$ each with length $l_{i} i=1, \cdots, m$ respectively, then for each positive integer $l$ there must be at least $[m(l-1) / l]$ intervals $I_{i}$ for which $l_{i} \leqq(l(b-a) / m)$.

Proof. The proof of this is elementary and is omitted.

LEMMA 4.7. Let $m \geqq 2$ be an integer and let $z_{0}<z_{1}<\cdots<z_{m}$ be given. Define $h\left[z_{0}, \cdots, z_{m}\right]=\sum_{j=0}^{m} \prod_{\substack{k=0 \\ k \neq j}}^{m}\left|z_{j}-z_{k}\right|^{-1}$. Then

$$
\left(z_{m}-z_{0}\right) h\left[z_{0}, \cdots, z_{m}\right] \geqq(m+1)\left(z_{m}-z_{0}\right)^{-m+1}
$$




$$
\begin{aligned}
& \left(z_{m}-z_{0}\right)\left(z_{m}-z_{1}\right) h\left[z_{0}, \cdots, z_{m}\right] \geqq\left(z_{m}-z_{0}\right)^{-m+2} \\
& \left(z_{m}-z_{0}\right)\left(z_{m-1}-z_{0}\right) h\left[z_{0}, \cdots, z_{m}\right] \geqq\left(z_{m}-z_{0}\right)^{-m+2} .
\end{aligned}
$$

Proof. The proof of (11) is easy. The proofs of (12) and (13) are obtained by considering the terms $j=1$ and $j=0$ in the sum respectively.

LEMMA 4.8. If $f\left[x_{0}, \cdots, x_{r+1}\right] \geqq 0$ for all $x_{0}<\cdots<x_{r+1}$ in $[-1-\epsilon, 1+\epsilon]$ for some $\epsilon>0$ then $f\left[t_{0}, \cdots, t_{r}\right]$ is bounded on $[-1,+1]$.

Proof. Use the above mentioned result in [2] that

$$
f \in C^{r-1}(-1-\epsilon, 1+\epsilon)
$$

and therefore that $f^{(r-1)}$ is convex on $(-1-\epsilon, 1+\epsilon)$.

We now proceed with the proof of Theorem 3.1 and its corollaries. Let $f$ have bounded $r$ th order divided differences and nonnegative $(r+1)$-st order divided differences on $[-1,+1]$. Assume that for $n$ sufficiently large we have $p_{n}^{\langle r+1\rangle}(x) \geqq 0$ on $[-1,+1]$. We will show that this gives a constant $M>0$ for which

$$
E_{n}(f) \leqq M /(n+1)^{r+1} \text { for } n=0,1,2, \cdots \text {. }
$$

This will give Theorem 3.1. Corollary 3.1(a) will then follow from Theorem 3.1 and Lemma 4.2. Corollary 3.1(b) follows from Theorem 3.1 and Lemma 4.8 .

Proof of Theorem 3.1. Let $n \geqq r$ and let $x_{0}<x_{1}<\cdots<x_{n+1}$ be a Chebyshev alternation for $f$. Assume that there is a positive integer $N$ so that for all $n \geqq N$ we have $p_{n}^{\langle r+1\rangle}(x) \geqq 0$ on $[-1,+1]$, and let $n \geqq N$.

Now

$$
f\left(x_{i}\right)=p_{n}\left(x_{i}\right)+\varepsilon(-1)^{i} E_{n}(f)
$$

for $i=0,1, \cdots, n+1$ where $\varepsilon= \pm 1$ is fixed relative to $i$. Let $g$ be any function which satisfies

$$
g\left(x_{i}\right)=(-1)^{i} \text { for } i=0,1, \cdots, n+1 .
$$

Then

$$
f\left(x_{i}\right)=p_{n}\left(x_{i}\right)+\varepsilon E_{n}(f) g\left(x_{i}\right)
$$

for $i=0,1,2, \cdots, n+1$. 
From [3] p. 247 we have the identity

$$
F\left[x_{0}, \cdots, x_{m}\right]=\sum_{j=0}^{m} F\left(x_{j}\right) \prod_{\substack{k=0 \\ k \neq j}}^{m}\left(x_{j}-x_{k}\right)^{-1} .
$$

If $i+r+1 \leqq n+1$ we have

$$
g\left[x_{i}, \cdots, x_{i+r+1}\right]=\sum_{j=0}^{r+1}(-1)^{i+j} \prod_{\substack{k=0 \\ k \neq j}}^{r+1}\left(x_{i+j}-x_{i+k}\right)^{-1} .
$$

We note that all terms in the sum on the right of (16) have the same sign. If $\varepsilon$ is as in (14) and if

$$
(-1)^{i} \varepsilon \prod_{k=1}^{r+1}\left(x_{i}-x_{i+k}\right)^{-1}>0
$$

we have from (16)

$$
\varepsilon g\left[x_{i}, \cdots, x_{i+r+1}\right]=h\left[x_{i}, \cdots, x_{i+r+1}\right]
$$

where $h$ is as in Lemma 4.7 .

From (11) and (17) we have

$$
\varepsilon\left(x_{i+r+1}-x_{i}\right) g\left[x_{i}, \cdots, x_{i+r+1}\right] \geqq(r+2)\left(x_{i+r+1}-x_{i}\right)^{-r} .
$$

Now using (14), (17), and (19) and the assumption that $p\left[x_{i}, \cdots, x_{i+r+1}\right] \geqq 0$ we have

(20) $\quad\left(x_{\imath+r+1}-x_{2}\right) f\left[x_{i}, \cdots, x_{i+r+1}\right] \geqq E_{n}(f)\left(x_{i+r+1}-x_{i}\right)^{-r}(r+2)$.

There are at least $t_{n}=[(n-r+1) / 2]$ points $x_{i}$ in $[-1,+1]$ for which (17) holds. We now consider non-overlapping sets $\left\{x_{i}, \cdots\right.$, $\left.x_{i+\boldsymbol{r}+1}\right\}$ where (17) holds for $x_{i}$. There are at least

$$
m=\left[\frac{t_{n}}{r+2}\right]
$$

such sets, and by Lemma 4.6 there are at least $[\mathrm{m} / 2]$ such sets with $x_{i+r+1}-x_{i} \leqq 4 / m$. It is clear that there is a constant $K>0$ for which

$$
\frac{4}{m} \leqq \frac{K}{n} \quad \text { for } \quad m \geqq 1
$$

Thus $x_{i+r+1}-x_{i} \leqq K / n$ for $n$ sufficiently large.

Now we sum (20) over all such sets and use this to get

$$
K_{1}\left[\frac{m}{2}\right]\left(\frac{n}{K}\right)^{r} E_{n}(f) \leqq \sum_{i}\left(x_{i+r+1}-x_{i}\right) f\left[x_{i}, \cdots, x_{i+r+1}\right] .
$$


Clearly there is $K_{2}>0$ for which

$$
\begin{aligned}
E_{n}(f) & \leqq \frac{K_{2}}{n^{r+1}} \sum_{i}\left(x_{i+r+1}-x_{i}\right) f\left[x_{i}, \cdots, x_{i+r+1}\right] \\
& =\frac{K_{2}}{n^{r+1}} \sum_{i}\left(f\left[x_{i+1}, \cdots, x_{i+r+1}\right]-f\left[x_{i}, \cdots, x_{i+r}\right]\right) \\
& \leqq \frac{2 K_{2} M^{*}}{n^{r+1}}
\end{aligned}
$$

where $M^{*}=\max \left\{\left|f\left[t_{0}, \cdots, t_{r}\right]\right|:-1 \leqq t_{0}<\cdots<t_{r} \leqq 1\right\}$. This proves Theorem 3.1.

For the proof of Theorem 3.2 we use (12) and (13) and the fact that $f^{(r-1)}$ is of bounded variation. The proof proceeds as above except that $f\left[x_{i}, \cdots, x_{i+r+1}\right]$ is written in terms of $(r-1)$ st order divided differences and therefore in terms of $f^{(r-1)}$. We omit the details here.

Corollary 3.2 is a simple consequence of Lemma 4.2 and Theorem 3.2.

For the proof of Theorems 3.3 and 3.4 we may as well assume that $\omega$ is concave in view of (8). The proofs will be done simultaneously. We will work on $[-2,2]$ here instead of on $[-1,1]$.

Proofs of Theorem 3.3 and Theorem 3.4. Let $\varepsilon>0$ be given and let $\omega$ be any concave modulus of continuity. Define

$$
g(x)= \begin{cases}\varepsilon\left(x^{2}+5 x+1\right) & \text { on }[-2,-1] \\ (x-1)^{2}+|x|+(5+3 \varepsilon) x & \text { on }[-1,+1] \\ 3(2+\varepsilon) x^{2}+\omega(1)-\omega(2-x) & \text { on }[1,2]\end{cases}
$$

$g$ is easily seen to be continuous, increasing, and convex on $[-2,2]$. Moreover, $g^{\prime}(0)$ does not exist.

Let $g_{r}$ be an $r$ th order integral of $g$. Then $g_{r} \in C^{r}[-2,2]$ and

$$
g_{r}\left[t_{0}, \cdots t_{r+1}\right] \geqq \frac{\varepsilon}{(r+1) !}
$$

for

$$
-2 \leqq t_{0}<\cdots<t_{r+1} \leqq 2
$$

and

$$
g_{r}\left[t_{0}, \cdots, t_{r+2}\right] \geqq \frac{2 \varepsilon}{(r+2) !}
$$

for 


$$
-2 \leqq t_{0}<\cdots<t_{r+1}<t_{r+2} \leqq 2 .
$$

We will show that there are infinitely many $n$ for which we do not have $p_{n}^{\langle r+1\rangle}(x) \geqq 0$ on $[-2,+2]$ and infinitely many $n$ for which we do not have $p_{n}^{\langle r+2\rangle}(x) \geqq 0$ on $[-2,+2]$, where $p_{n}$ is the polynomial from $H_{n}$ of best approximation to $g_{r}$. This will be sufficient for the proofs of both theorems in view of the fact that for $0 \leqq h \leqq 1$

$$
\omega(h) \leqq \omega(g, h) \leqq K \omega(h),
$$

which is easy to show. The proof of (24) is essentially the same as the proof of (16) in [12]. It is easy to see that on $[-1,+1]$ we have $g_{r}(x)=C x_{+}^{r+1}+D q_{r}(x)$ where $q_{r} \in H_{r+2}$, and where $C$ depends only on $r$. In view of this and Lemma 4.5 we have

$$
E_{n}\left(g_{r}\right) \geqq \frac{K_{r}}{(n+1)^{r+1}} \quad \text { for } \quad n=0,1, \cdots,
$$

where $K_{r}$ depends only on $r$.

$$
\text { If }-2 \leqq t_{0}<\cdots<t_{r+1} \leqq-1 \text { then }
$$

$$
g_{r}\left[t_{0}, \cdots, t_{r+1}\right] \leqq \frac{3 \varepsilon}{(r+1) !}
$$

and if $-2 \leqq t_{0}<\cdots<t_{r+2} \leqq-1$ then

$$
g_{r}\left[t_{0}, \cdots, t_{r+2}\right]=\frac{2 \varepsilon}{(r+2) !}
$$

Now assume that $p_{n}^{\langle r+1\rangle}(x) \geqq 0$ on $[-2,+2]$ for $n$ sufficiently large. Then as in the proof of Theorem 3.1 we choose a Chebyshev alternation for such $n$

$$
-2 \leqq x_{0}<x_{1}<\cdots<x_{n+1} \leqq 2
$$

and for $g_{r}$ and obtain

$$
g_{r}\left[x_{i}, \cdots, x_{i+r+1}\right] \geqq \sigma E_{n}\left(g_{r}\right) y\left[x_{i}, \cdots, x_{i+r+1}\right]
$$

where $\sigma= \pm 1$ is independent of $i$, and $y$ is any function for which $y\left(x_{i}\right)=(-1)^{i} i=0,1, \cdots, n+1$.

Now by Lemma 4.3 there is a sequence $\left\{n_{j}\right\}_{j=0}^{\infty}$ for which $\lim _{j \rightarrow \infty} \delta_{n_{j}}=0$. Thus for $j$ sufficiently large $1 / 4$ of the $n_{j}+2$ Chebyshev alternation points for $g_{r}$ lie in $[-2,-1]$. Thus there is a constant $K$ depending only on $r$ such that for $j$ sufficiently large there are $r+2$ alternation points $x_{i}, \cdots, x_{i+r+1}$ in $[-2,-1]$ with 


$$
x_{i+r+1}-x_{i} \leqq \frac{K}{n_{j}+1}
$$

and for which

$$
\sigma y\left[x_{i}, \cdots, x_{i+r+1}\right] \geqq 0 .
$$

An application of (11) now gives

$$
\sigma y\left[x_{i}, \cdots, x_{i+r+1}\right] \geqq \frac{(r+2)}{K^{r+1}}\left(n_{j}+1\right)^{r+1} .
$$

Thus from (26), (28), and (31) we get for $j$ sufficiently large

$$
E_{n_{j}}\left(g_{r}\right) \leqq \frac{K^{r+1}}{(r+2) !} \cdot 3 \varepsilon\left(\frac{1}{\left(n_{j}+1\right)^{r+1}}\right) .
$$

This together with (25) gives

$$
K_{r} \leqq \frac{3 K^{r+1}}{(r+2) !} \varepsilon
$$

But for $\varepsilon$ sufficiently small this can easily be violated. Thus we have a contradiction.

To show that we cannot have $p_{n}^{\langle r+2\rangle}(x) \geqq 0$ for $n$ sufficiently large we proceed in similar fashion. We use (27) and obtain a sequence $\left\{n_{j}\right\}_{j=0}^{\infty}$ for which

$$
E_{n_{j}}\left(g_{r}\right) \leqq \frac{2 C_{r}^{r+2}}{(r+3) !} \cdot \frac{\varepsilon}{\left(n_{j}+1\right)^{r+2}} .
$$

This together with (25) gives an obvious contradiction. We omit the proof of (33) since it is the same as the proof of (32).

We remark that the existence of a $g \in C[-2,2]$ such that (24) holds implies the existence of $A>1, \mathrm{~B}>0$ such that

$$
\omega(h) \leqq \omega(A g, h) \leqq B \omega(h),
$$

for $0 \leqq h \leqq 4$. Thus both theorems are proven.

\section{REFERENCES}

1. S. N. Bernstein, Collected Works, AEC Tr. No. 3460, (1952), 175.

2. R. P. Boas and D. V. Widder, Functions with positive differences, Duke Math.

J. 7 (1940), 496-503.

3. E. Isaacson and H. B. Keller, Analysis of Numerical Methods, John Wiley and Sons, New York, 1966.

4. M. I. Kadec, On the distribution of points of maximum deviation in the approximation of continuous functions by polynomials, Amer. Math. Soc. Translations (2), 26 (1963), 231-234. 
5. G. G. Lorentz, Approximation of Functions, Holt, Rinehart and Winston, New York, 1966.

6. Monotone approximation, Inequalities III, (O. Shisha, Ed.), pp. 201-215, Academic Press Inc., 1969.

7. G. G. Lorentz and K.L. Zeller, Monotone approximation by algebraic polynomials, Trans. Amer. Math. Soc., 149 (1970), 1-18.

8. G. G. Lorentz and K. L. Zeller, Degree of appaoximation by monotone polynomials II, J. Approximation Theory, 2 (1969), 265-269.

9. J. A. Roulier, Monotone and weighted approximation, Dissertation, Syracuse University, 1968.

10. - Polynomials of best approximation which are monotone, J. Approximation Theory, 9 (1973), 212-217.

11. - Best approximation to functions with restricted derivatives, J. Approximation Theory (to appear).

12. - Negative theorems on monotone approximation, Proc. Amer. Math. Soc., 55 (1976), 37-43.

13. S. B. Steckin, On the order of the best approximation of continuous functions, Izv., 15 (1951), 219-242.

Received November 13, 1975 and in revised form March 15, 1976. The first author was supported in part by Temple University Grant-in-Aid of Research, Number 700-050-85.

North Carolina State University-Raleigh

AND

Temple University 



\section{PACIFIC JOURNAL OF MATHEMATICS}

\section{EDITORS}

RICHARD ARENS (Managing Editor)

University of California

Los Angeles, California 90024

\section{R. A. Beaumont}

University of Washington

Seattle, Washington 98105
J. DugundjI

Department of Mathematics

University of Southern California

Los Angeles, California 90007

D. Gilbarg and J. Milgram

Stanford University

Stanford, California 94305

\section{ASSOCIATE EDITORS}
E. F. BECKENBACH
B. H. NeumanN
F. WOLF
K. YosHIDA

\section{SUPPORTING INSTITUTIONS}

\author{
UNIVERSITY OF BRITISH COLUMBIA \\ CALIFORNIA INSTITUTE OF TECHNOLOGY \\ UNIVERSITY OF CALIFORNIA \\ MONTANA STATE UNIVERSITY \\ UNIVERSITY OF NEVADA \\ NEW MEXICO STATE UNIVERSITY \\ OREGON STATE UNIVERSITY \\ UNIVERSITY OF OREGON \\ OSAKA UNIVERSITY
}

\author{
UNIVERSITY OF SOUTHERN CALIFORNIA \\ STANFORD UNIVERSITY \\ UNIVERSITY OF HAWAII \\ UNIVERSITY OF TOKYO \\ UNIVERSITY OF UTAH \\ WASHINGTON STATE UNIVERSITY \\ UNIVERSITY OF WASHINGTON \\ AMERICAN MATHEMATICAL SOCIETY
}

The Supporting Institutions listed above contribute to the cost of publication of this Journal, but they are not owners or publishers and have no responsibility for its content or policies.

Mathematical papers intended for publication in the Pacific Journal of Mathematics should be in typed form or offset-reproduced, (not dittoed), double spaced with large margins. Please do not use built up fractions in the text of your manuscript. You may however, use them in the displayed equations. Underline Greek letters in red, German in green, and script in blue. The first paragraph or two must be capable of being used separately as a synopsis of the entire paper. Items of the bibliography should not be cited there unless absolutely necessary, in which case they must be identified by author and Journal, rather than by item number. Manuscripts, in triplicate, may be sent to any one of the editors. Please classify according to the scheme of Math. Reviews, Index to Vol. 39. All other communications should be addressed to the managing editor, or Elaine Barth, University of California, Los Angeles, California, 90024.

The Pacific Journal of Mathematics expects the author's institution to pay page charges, and reserves the right to delay publication for nonpayment of charges in case of financial emergency.

100 reprints are provided free for each article, only if page charges have been substantially paid. Additional copies may be obtained at cost in multiples of 50 .

The Pacific Journal of Mathematics is issued monthly as of January 1966. Regular subscription rate: $\$ 72.00$ a year (6 Vols., 12 issues). Special rate: $\$ 36.00$ a year to individual members of supporting institutions.

Subscriptions, orders for back numbers, and changes of address should be sent to Pacific Journal of Mathematics, 103 Highland Boulevard, Berkeley, California, 94708.

PUBLISHED BY PACIFIC JOURNAL OF MATHEMATICS, A NON-PROFIT CORPORATION

Printed at Kokusai Bunken Insatsusha (International Academic Printing Co., Ltd.), 8-8, 3-chome, Takadanobaba, Shinjuku-ku, Tokyo 160, Japan. 


\section{Pacific Journal of Mathematics \\ Vol. 65, No. $2 \quad$ October, 1976}

Andrew Adler, Weak homomorphisms and invariants: an example .......... 293

Howard Anton and William J. Pervin, Separation axioms and metric-like

functions ............................................. 299

Ron C. Blei, Sidon partitions and p-Sidon sets .................... 307

T. J. Cheatham and J. R. Smith, Regular and semisimple modules ........... 315

Charles Edward Cleaver, Packing spheres in Orlicz spaces .............. 325

Le Baron O. Ferguson and Michael D. Rusk, Korovkin sets for an operator on a

space of continuous functions ............................. 337

Rudolf Fritsch, An approximation theorem for maps into Kan fibrations ....... 347

David Sexton Gilliam, Geometry and the Radon-Nikodym theorem in strict

Mackey convergence spaces .................................

William Hery, Maximal ideals in algebras of topological algebra valued

functions ...................................... 365

Alan Hopenwasser, The radical of a reflexive operator algebra ........... 375

Bruno Kramm, A characterization of Riemann algebras................. 393

Peter K. F. Kuhfittig, Fixed points of locally contractive and nonexpansive

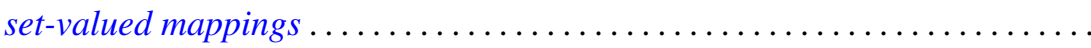

Stephen Allan McGrath, On almost everywhere convergence of Abel means of

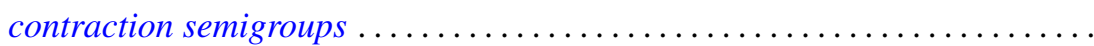

Edward Peter Merkes and Marion Wetzel, A geometric characterization of

indeterminate moment sequences............................ 409

John C. Morgan, II, The absolute Baire property ................... 421

Eli Aaron Passow and John A. Roulier, Negative theorems on generalized convex approximation .................................... 437

Louis Jackson Ratliff, Jr., A theorem on prime divisors of zero and characterizations of unmixed local domains ..............

Ellen Elizabeth Reed, A class of $T_{1}$-compactifications................... 471

Maxwell Alexander Rosenlicht, On Liouville's theory of elementary

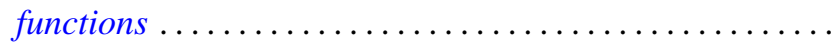

Arthur Argyle Sagle, Power-associative algebras and Riemannian

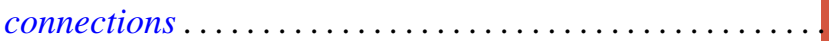

Chester Cornelius Seabury, On extending regular holomorphic maps from Stein manifolds...

Elias Sai Wan Shiu, Commutators and numerical ranges of powers of operators ...................................

Donald Mark Topkis, The structure of sublattices of the product of $n$ lattices ... 525

John Bason Wagoner, Delooping the continuous $K$-theory of a valuation

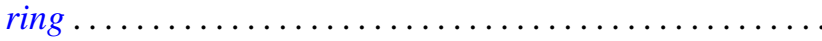

Ronson Joseph Warne, Standard regular semigroups...........

Anthony William Wickstead, The centraliser of $E \otimes_{\lambda} F \ldots$. 